\title{
Ocorrência e controle de Curculionidae em Cocos nucifera L. em Sinop, Mato Grosso
}

\section{Occurrence and control of weevils in Cocos nucifera L. in Sinop, Mato Grosso}

\author{
Ivan Luiz Dal Molin'; Marliton Rocha Barreto²
}

\begin{abstract}
Resumo
A incidência de pragas nos coqueirais constitui um fator limitante à exploração, respondendo de maneira significativa pelo depauperamento geral da cultura e também pela redução da produtividade, visto que grande parte do coqueiral brasileiro é cultivado por pequenos produtores sem acesso à tecnologia e a recursos financeiros, o que aumenta ainda mais a precariedade no manejo dessas enfermidades. Dessa forma, o objetivo deste trabalho foi verificar os curculionideos-praga na cultura do coco na região de Sinop, MT a apresentar possíveis métodos de controle. O experimento foi conduzido em três propriedades com cultivo de coco (Cocos nucifera L.) em Sinop, Mato Grosso, Brasil, no período de setembro de 2009 a abril de 2010. Para a coleta foram utilizadas armadilhas Tipo Balde e Tipo Pet espalhadas dentro dos coqueirais e os resultados indicaram o primeiro registro da ocorrência de Metamasius cinnamominus Perty 1830, Metamasius hemipterus hemipterus Linnaeus, 1765 e Rhynchophorus palmarum Linnaeus 1758 no estado de Mato Grosso e de Rhinostomus barbirostris Fabricius 1775, na região de Sinop, além de Homalinotus coriaceus Gyllenhal, 1836 e Amerrhinus ynca Sahlberg, 1823. Dados de distribuição e controle também são apresentados.
\end{abstract}

Palavras-chave: Insecta. Coleoptera. Pragas do coqueiro. Amazônia meridional.

\begin{abstract}
The incidence of pests in coconut trees is a factor that limits its cultivation, accounting for a significant depletion of the culture as well as for reducing productivity, considering that, in Brazil, coconut is mostly cultivated by small farmers who do not have access to technology and financial resources, thus increasing the precariousness of disease control. Therefore, the objective of this study was to identify the curculionidae-pests in coconut cultures in the region of Sinop - Mato Grosso, and present possible control methods. The experiment was conducted at three coconut (Cocos nucifera L.) farms in Sinop, Mato Grosso, Brazil, from September 2009 to April 2010. Bucket and PET (Polyethylene terephthalate) bottle traps were used to collect the samples. The traps were spread among the coconut trees, and the results indicated the first record of Metamasius cinnamominus Perty 1830, Metamasius hemipterus hemipterus Linnaeus, 1765 and Rhynchophorus palmarum Linnaeus, 1758 in the State of Mato Grosso, and of Rhinostomus barbirostris Fabricius, 1775, in the Sinop region, as well as Homalinotus coriaceus Gyllenhal, 1836 and Amerrhinus ynca Sahlberg, 1823. Distribution and control data are also presented. Keywords: Insecta. Coleoptera. Coconut pests. Meridional Amazon.
\end{abstract}

\footnotetext{
${ }^{1}$ Graduado em Agronomia. Universidade Federal de Mato Grosso, Agrárias e Ambientais - ICAA. Avenida Alexandre Ferronato, 1200. CEP 78.557-267. Sinop, MT, Brasil. E-mail. ivanluizdalmolin@gmail.com

2 Dr. em Entomologia. Docente do Programa de Pós-graduação em Ciências Ambientais da Universidade Federal de Mato Grosso, Instituto de Ciências Naturais Humanas e Sociais. Núcleo de Estudo da Biodiversidade da Amazônia Matogrossense. Avenida Alexandre Ferronato, 1200. CEP 78.557-267. Sinop, MT, Brasil.* Autor para correspondência. E-mail. mrbarreto@ufmt.br
} 


\section{Introdução}

O coqueiro (Cocos nucifera L.) é uma monocotiledônea pertencente à família Palmae e à subfamília Cocoideae (SOUZA, 2006). Originado no sudeste da Ásia foi introduzida no Brasil através do estado da Bahia (MIRISOLA FILHO, 2002), sendo esse, segundo o IBGE (2009), o maior produtor brasileiro com 79.596 ha, produção de 467.080 toneladas e produtividade de $5.868 \mathrm{~kg} / \mathrm{ha}$.

O Mato Grosso, pela sua proximidade com os países do Mercosul e pela possibilidade do escoamento fluvial da produção, apresenta grande potencial para a cocoicultura irrigada (FONTES; FERREIRA; SIQUEIRA, 2002). Para Mirisola Filho (2002), o aumento da procura e do consumo do coco verde "in natura", tem sido responsável pela expansão da cocoicultura na região Centro-Oeste. Segundo Faria, Gaiva e Pereira (2002), a cocoicultura no Mato Grosso vem se expandindo consideravelmente, tendo como principal empecilho para expansão, as dificuldades em se obter genótipos produtivos e de variedades comprovadamente adaptadas à região. Neste mesmo ano, a produção mato-grossense foi de 20.673 toneladas, com área colhida de 1.798 ha e rendimento médio de $11.497 \mathrm{~kg} / \mathrm{ha}$ (IBGE, 2009).

Em Sinop a produção de coco é pouco expressiva, porém promissora, devido principalmente à elevada disponibilidade hídrica para sistemas de irrigação, solo favorável ao cultivo, topografia pouco acentuada e grandes áreas disponíveis as atividades agrícolas. No ano de 2009, a produção da região foi de $640 \mathrm{mil}$ frutos com uma área plantada e colhida de 80 ha, apresentando rendimento médio de 8.000 frutos/ha (IBGE, 2009).

A incidência de pragas nos coqueirais constitui um fator limitante a exploração, respondendo de maneira significativa pelo depauperamento geral da cultura e também pela redução da produtividade, visto que grande parte do coqueiral brasileiro é cultivado por pequenos produtores sem acesso à tecnologia e a recursos financeiros, aumentando ainda mais a precariedade no manejo dessas enfermidades
(MOURA; VILELA, 1998).

As injúrias causadas pelos insetos-praga ocasionam prejuízos consideráveis na cultura em diferentes estágios de crescimento e desenvolvimento, e podem ser observados desde a implantação da cultura. Elas ocasionam grande número de replantios, atraso no desenvolvimento vegetativo e consequentemente atraso do início da produção, até em níveis de desenvolvimento em que a planta já atingiu a fase adulta, e ainda quando está morta, servindo como foco de multiplicação desses agentes (FERREIRA; WARWICK; SIQUEIRA, 1998).

Estima-se que cerca de 547 insetos e ácaros atacam o coqueiro em todo o mundo (MIRISOLA FILHO, 2002). Entre as pragas de maior importância, destacam-se aquelas associadas aos frutos do coqueiro, como ácaros e a traça, às associadas a partes específicas da planta, como os desfolhadores, as brocas (Curculionídeos) e outros insetos como sugadores, raspadores, entre tantas espécies (FERREIRA, 2006a).

Os curculionídeos são coleópteros da superfamília Curculionoidae com cerca de 60.000 espécies descritas. São conhecidos por gorgulhos e facilmente identificados pela presença de antenas genículoclavadas, assim como pela cabeça prolongada em um rostro de comprimento muito variável. Adultos e larvas são geralmente fitófagos, e podem alimentarse praticamente de qualquer parte viva ou morta dos vegetais. Várias espécies são daninhas às plantas cultivadas ou aos grãos armazenados, outras entretanto, são importantes agentes polinizadores (AMBROGI et al., 2009).

De maneira geral, os danos que os curculionídeos apresentam são ocasionados na fase larval e pela perfuração de tecidos para oviposição e/ ou alimentação. Ao eclodirem, as larvas fazem galerias nos tecidos das plantas, principalmente na gema apical, no pecíolo das folhas novas, nas inflorescências e no estipe mole, destruindo os tecidos condutores de seiva podendo ocasionar a morte 
da planta (AMBROGI et al., 2009; SALOMÃO; SIQUEIRA, 2007).

As pragas das palmeiras são encontradas em vários locais do Brasil, podendo uma espécie ter sua importância alterada de acordo com a localidade. $\mathrm{Na}$ região norte do Mato Grosso, as pesquisas voltadas para a produção, manejo de pragas e doenças, adaptação da cultura do coco encontramse incipientes ou quase inexistentes, dificultando a informação e tomada de decisão dos produtores e técnicos da área. Dessa forma, o objetivo deste trabalho foi verificar os curculionideos-praga na cultura do coco na região de Sinop, MT a apresentar possíveis métodos de controle.

\section{Material e Métodos}

\section{Área de estudo}

Sinop, MT está localizada a 1150'53"

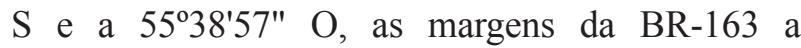
aproximadamente 384 metros de altitude. O experimento foi conduzido em três propriedades no período de setembro de 2009 a abril de 2010 . A Propriedade I está localizada a $11^{\circ} 53^{\prime} 44^{\prime \prime} \mathrm{S}$, $55^{\circ} 30^{\prime} 48^{\prime \prime} \mathrm{O}$, apresenta 7,4 hectares de coqueiral, contendo 1933 plantas com idade variando entre 7 e 12 anos, plantadas com espaçamento de $6 \times 6 \mathrm{~m}$.. A

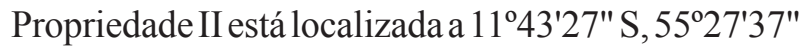
$\mathrm{O}$, apresenta somente um hectare de coqueiral com 221 plantas, com idade de 9 anos, plantadas com espaçamento de $6 \times 6 \mathrm{~m}$. A Propriedade III está localizada a $11^{\circ} 52^{\prime} 57^{\prime \prime} \mathrm{S}, 55^{\circ} 29^{\prime} 30^{\prime \prime} \mathrm{O}$, apresenta 2,2 hectares de coqueiral contendo 450 plantas com idade de 8 anos, plantadas com espaçamento de 6 x $6 \mathrm{~m}$.

\section{Metodologia de Coleta}

Para a captura dos curculionídeos, foram utilizadas armadilhas Tipo Balde (Alçapão) e armadilha Tipo Pet. A armadilha Alçapão consistiu de balde plástico de 65 litros com tampa, dentro do qual foram colocados 15 toletes amassados de cana-de-açúcar com $40 \mathrm{~cm}$ de comprimento cada, conforme Moura et al. (1990). Sob a tampa do balde foram feitos quatro orifícios eqüidistantes e em cada um deles foi acoplado com arames um funil plástico de $10 \mathrm{~cm}$ de diâmetro, com a parte estreita do funil cortada e voltada para o interior do balde para permitir a passagem dos insetos. Atraídos pelos odores emanados da isca da cana, ao pousarem na tampa os insetos escorregam através dos funis e ficam presos no interior do balde.

A armadilha tipo Pet (FERREIRA; ARAÚJO; SARRO, 2001) é confeccionada basicamente com três garrafas plásticas de refrigerante, compondose das seguintes partes: Parte " $A$ " - garrafa com o gargalo voltado para baixo, formando um funil que permite a entrada da praga; Parte " $B$ " - garrafa cortada a meio centímetro do final da parte afunilada e que serve como câmara de captura dos adultos; Parte " $C$ " - garrafa, da qual é retirado o fundo e a parte afunilada do gargalo que serve para a fixação das partes A e B. A parte "C" da armadilha foi fixada na parte " $A$ " com pedaços de arame e na parte "B" pela pressão das duas garrafas entre si facilitando a troca dos toletes de cana-de-açúcar e a coleta dos adultos. $\mathrm{Na}$ armadilha foram feitos pequenos furos, tanto no fundo, para evitar acúmulo de água (parte "B"), como nas laterais (partes " $\mathrm{B}$ " e "C"), para facilitar a aeração no interior da câmara de captura e a difusão do odor dos atrativos para o exterior da armadilha. Em cada Pet foram colocados 2 a 3 toletes de cana-de-açúcar amassados, com cerca de $10 \mathrm{~cm}$ de comprimento cada e algumas fatias do mesocarpo (parte fibrosa) do fruto do coqueiro.

Para a propriedade I, foram utilizados dez baldes, espalhados ao acaso, dentro do coqueiral, com distância mínima de $25 \mathrm{~m}$. entre um e outro, com início das coletas no dia 11/09/2009. Posteriormente foram utilizadas dez armadilhas Pet, amarradas com barbantes no estipe do coqueiro próximo a inflorescência, também distribuídas ao acaso como os baldes, a fim de capturar os insetos localizados na copa do coqueiro, onde geralmente ficam abrigados. 
O período de coletas das propriedades II e III teve início no dia 05/02/2010 num total de 6 Baldes e 6 Pets para cada local, espalhadas dentro do coqueiral ao acaso, mantendo a eqüidistância de 25 metros. A coleta procedeu-se semanalmente até 04/04/2010.

As coletas foram realizadas semanalmente coletando os insetos manualmente do interior da armadilha e colocando-os em potes plásticos com tampa, onde foi anotado o dia da coleta e o número correspondente a armadilha utilizada. A troca dos toletes procedeu-se quinzenalmente dependendo do estado físico dos mesmos (LACERDA, 2001). Se estivessem podres ou secos, eram substituídos por pedaços novos e os demais eram mantidos para que restasse parte da cana já fermentada, fato que ajuda na atração dos insetos.

Após cada coleta, os insetos foram levados para o laboratório de Entomologia do ICNHS/UFMT Sinop, onde foram montados, secados e depositados na coleção entomológica do ABAM/UFMT Sinop. Para posterior identificação, os insetos foram enviados para o prof. Dr. Germano H. Rosado-Neto da UFPR.

Dados de precipitação pluviométrica do município de Sinop, referentes aos meses de coleta, foram obtidos Empaer Sinop-INMET, cuja finalidade foi verificar sua possível influência sobre o número de insetos coletados. Os dados sobre a distribuição e controle dos insetos aqui apresentados foram obtidos em literaturas especializadas diversas.

\section{Resultados e Discussão}

\section{Ocorrência dos Insetos-Praga}

Foram obtidos os seguintes curculionídeospraga: Rhynchophorus palmarum Linnaeus, 1758, Rhinostomus barbirostris Fabricius, 1775, Homalinotus coriaceus Gyllenhal, 1836, Metamasius cinnamominus (Perty, 1832), Metamasius hemipterus hemipterus (Linnaeus, 1758) e Amerrhinus ynca Sahlberg, 1823. Todos com primeiro registro de ocorrência na região de Sinop e, conseqüentemente, no Mato Grosso, exceto R. barbirostris que teve sua ocorrência relatada no município de Cotriguaçu (SILVA, 2009). A existência de Homalinotus coriaceus e Amerrhinus ynca é conhecida na região em função de alguns exemplares destes insetos terem sido coletados no ano de 2008, os quais podem ser observados na coleção de entomologia (ABAM/ UFMT), porém durante a condução do experimento exemplares dos mesmos não foram capturados.

Dentre os 2.154 (Tabela 1) insetos coletados do gênero Metamasius, apenas 10 corresponderam à espécie Metamasius cinnamominus (Perty, 1832), sendo oito exemplares coletados na propriedade I e dois deles coletados na propriedade II. Os demais 2.144 foram da espécie Metamasius hemipterus hemipterus (Linnaeus, 1758).

Tabela 1 - Curculionídeos coletados em Cocos nucifera em Sinop, MT no período de setembro/2009 a abril/2010.

\begin{tabular}{lccccc}
\hline Propriedade & \multicolumn{2}{c}{ Insetos-Praga } & Plantas $\left(\mathrm{n}^{\mathrm{o}}\right)$ \\
\hline & $\begin{array}{c}\text { Rhynchophorus } \\
\text { palmarum }\end{array}$ & $\begin{array}{c}\text { Metamasius hemipterus } \\
\text { hemipterus }\end{array}$ & $\begin{array}{c}\text { Metamasius } \\
\text { barbirostris }\end{array}$ & $\begin{array}{c}\text { Rhinostomus } \\
\text { cinnamominus }\end{array}$ \\
\hline I & 233 & 840 & 08 & 00 & 1.933 \\
II & 86 & 740 & 02 & 01 & 221 \\
III & 86 & 574 & & 00 & 450 \\
\hline TOTAL & 405 & 2.144 & 10 & 01 & - \\
\hline
\end{tabular}

Fonte: Autores. 
A relação do número de Rhynchophorus palmarum e Metamasius coletados foi superior na propriedade I em relação às demais propriedades (Tabela 1). A propriedade I apresentou uma infestação superior das pragas que nas outras propriedades, visto que nessa área a porcentagem de plantas com sintomas da ação de $R$. palmarum também foi superior (Tabela 1). Os ferimentos deixados pela ação do R. palmarum, expõem o tecido da planta no ambiente e podem atrair a brocarajada (Metamasius) para a planta aonde vem a procriar (ZORZENON; BERGMANM; BICUDO, 2000). Segundo esses autores, a grande quantidade de Metamasius coletados pode ser atribuída também pelo fato de que os restos culturais como estipe, folha, pedúnculo, são depositados nas entrelinhas da propriedade, o que favorece a incidência, pois servem de hospedeiras para a reprodução dessas pragas. Outra hipótese para essa diferença pode ser atribuída ao fato de a propriedade I possuir mais plantas que as demais ou o período de coleta ter sido maior (Tabela 1).

O número de insetos capturados do gênero Metamasius foi superior na propriedade II em relação à propriedade III (Tabela 1). Além do cultivo de coco, a propriedade II apresenta também produção de cana-de-açúcar, sendo esta hospedeira da praga, podendo assim ter contribuído para o aumento na população local (LEPESME, 1947), pois, durante a decomposição da cana ocorre à fermentação, dessa forma, alguns compostos voláteis são liberados no ambiente atraindo o inseto. Jaffé et al. (1993) estudaram voláteis de substrato, dentre eles o da cana-de-açúcar, e encontraram várias frações ativas como acetato de etila, pentanos, álcoois, entre outras, que quando testadas em laboratório exerceram atratividade sobre $R$. palmarum. Além disso, na propriedade II não é realizado o enterro ou queima dos restos culturais ou eles são depositados dentro da plantação nas entrelinhas, podendo assim contribuir na maior incidência do inseto (ZORZENON; BERGMANM; BICUDO, 2000).

Rhinostomus barbirostris apresentou-se praticamente ausente no período de coleta, sendo observado somente uma vez na propriedade II (Tabela 1). Esse acontecimento pode ser atribuído à população local da praga encontrar-se em níveis reduzidos ou ao método de captura, bem como o atrativo utilizado podem não ter sido adequado para a captura desses, levando em consideração que o inseto é de hábito noturno e permanece abrigado nas axilas das folhas durante o dia, dificultando à atratividade do inseto (FERREIRA; WARWICK; SIQUEIRA, 1998). Os manuais técnicos apresentam poucas informações devido à inexistência de pesquisas com bases científicas voltadas para o manejo dessa praga, constituindo uma problemática que limita a realização de estudos mais detalhados no momento, até mesmo em relação ao seu controle e método de captura (SARRO; CROCOMO; FERREIRA, 2004). 
Tabela 2 - Datas de coletas e porcentagem acumulada do total de Rhynchophorus palmarum e Metamasius hemipterus hemipterus coletados nas área de estudo em Sinop, MT. Propriedade = Prop.

\begin{tabular}{|c|c|c|c|c|c|c|c|c|}
\hline \multirow{2}{*}{$\begin{array}{l}\text { Prop. I } \\
\text { Datas } \\
\text { de } \\
\text { coleta }\end{array}$} & \multicolumn{2}{|c|}{ Insetos coletados $(\%)$} & \multirow{2}{*}{$\begin{array}{l}\text { Prop. II } \\
\text { Datas } \\
\text { de } \\
\text { coleta }\end{array}$} & \multicolumn{2}{|c|}{ Insetos coletados $(\%)$} & \multirow{2}{*}{$\begin{array}{l}\text { Prop. III } \\
\text { Datas } \\
\text { de } \\
\text { coleta }\end{array}$} & \multicolumn{2}{|c|}{ Insetos coletados $(\%)$} \\
\hline & $\begin{array}{l}R . \\
\text { palmarum }\end{array}$ & $\begin{array}{l}\text { M. } \\
\text { hemipterus } \\
\text { hemipterus }\end{array}$ & & $\begin{array}{l}R . \\
\text { palmarum }\end{array}$ & $\begin{array}{l}\text { M. } \\
\text { hemipterus } \\
\text { hemipterus }\end{array}$ & & $\begin{array}{l}R . \\
\text { palmarum }\end{array}$ & $\begin{array}{l}\text { M. } \\
\text { hemipterus } \\
\text { hemipterus }\end{array}$ \\
\hline 18-09-09 & 05,15 & 11,17 & $12-02-10$ & 10,46 & 18,24 & $12-02-10$ & 01,16 & 11,84 \\
\hline 26-09-09 & 18,88 & 25,47 & $21-02-10$ & 17,43 & 30,67 & $21-02-10$ & 10,46 & 19,68 \\
\hline 02-10-09 & 26,60 & 31,84 & $28-02-10$ & 33,70 & 41,61 & $28-02-10$ & 32,55 & 33,79 \\
\hline $10-10-09$ & 37,33 & 39,41 & $07-03-10$ & 39,51 & 49,04 & $07-03-10$ & 38,36 & 41,98 \\
\hline $17-10-09$ & 51,50 & 53,11 & $14-03-10$ & 56,95 & 60,25 & $14-03-10$ & 45,33 & 62,36 \\
\hline 24-10-09 & 58,35 & 62,36 & $21-03-10$ & 65,09 & 69,84 & $21-03-10$ & 52,3 & 73,33 \\
\hline 01-11-09 & 68,22 & 69,93 & $28-03-10$ & 80,20 & 87,81 & $28-03-10$ & 63,92 & 92,49 \\
\hline 07-11-09 & 73,37 & 75,10 & 04-04-10 & 100 & 100 & 04-04-10 & 100 & 100 \\
\hline $15-11-09$ & 79,80 & 81,95 & & & & & & \\
\hline 22-11-09 & 83,23 & 87,72 & & & & & & \\
\hline 29-11-09 & 92,24 & 94,45 & & & & & & \\
\hline 05-12-09 & 100 & 100 & & & & & & \\
\hline 78 dias & & & 51 dias & & & 51 dias & & \\
\hline
\end{tabular}

Fonte: Autores.

Analisando os valores da porcentagem acumulada do total de Rhynchophorus palmarum e Metamasius hemipterus hemipterus coletados para a propriedade I (Tabela 2), o valor de aproximadamente 50\% ocorreu na metade do mês de outubro/2009. No mês de setembro, foram poucas as precipitações registradas no município, totalizando $107 \mathrm{~mm}$ (Figura 1). Percebe-se, na tabela 02, que nas primeiras semanas do mês de outubro/2009, ocorre uma elevação rápida na porcentagem das pragas capturadas, e essa elevação coincide com uma elevação na precipitação para o mesmo mês (Figura 1). Essas observações indicam haver interferência da precipitação e do conseqüente aumento da umidade na quantidade de insetos capturados. Esta interação também foi observada por Araújo e Pereira (1998), em plantações de coqueiro, nas quais a captura dos insetos de cerca de $77 \%$ ocorreu no período de maior precipitação e Ferreira (2006b). Esses autores obtiveram resultados similares em experimento realizado em Aracaju/SE, no período de dezembro 1995 a novembro 1996.

A porcentagem acumulada do total de $R$. palmarum e $M$. hemipterus hemipterus coletados para as propriedade II e III (Tabela 2), também indicam haver uma possível interferência da precipitação na quantidade de insetos capturados, sendo que o valor de aproximadamente $50 \%$ ocorreu próximo a metade do mês de março/2010, quando houve uma elevação 
em 31\% na precipitação em relação a fevereiro/2010 (Figura 1). A precipitação pluviométrica tem sido registrado como fator de maior ou menor incidência de insetos praga por diversos autores como Azeredo, Costa e Medeiros (1998) que relataram que, para Cosmopolites sordidus Germar, 1824, à medida que ocorre aumento da precipitação há uma redução na população de insetos. Entretanto, Pavarini et al. (2009) relataram que as maiores incidências deste inseto, no município de Juquiá/ SP, na cultura da banana, estão relacionados à baixa precipitação pluviométrica, resultados semelhantes foram encontrados em bananal, cv. Nanicão, em São Miguel do Iguaçu/PR. Este mesmo autor cita ainda os trabalhos realizados por Arleu (1982), que, ao estudar a movimentação de adultos de $C$. sordidus em área de cultivo de banana 'Prata' no Espírito Santo, observou que esta se manteve uniforme durante todo o ano, havendo pouca influência da ação de elementos climáticos da região na flutuação da população. Também é citado Silva (1985), que correlacionando a flutuação populacional de $C$. sordidus com fatores meteorológicos no estado da Paraíba, encontrou correlação negativa entre a precipitação pluviométrica e o número de adultos. Ferreira et al. (2003) relataram que a variação na captura de adultos de $R$. palmarum, durante os meses do ano em que se desenvolveu o experimento (dez./95 a nov./96), mostrou maior concentração no período correspondente ao de maior precipitação, sendo que nos meses de abril e agosto, início e final do período chuvoso, verificou-se um elevado número de insetos e maior índice pluviométrico. Essas observações indicam haver interferência da precipitação e do consequente aumento da umidade na quantidade de insetos capturados. Esse fato também foi observado por Araujo e Pereira (1998), em plantações de coqueiro, onde a captura de cerca de $77 \%$ dos insetos ocorreu no período de maior precipitação. Vera e Orellana (1988) afirmam que a coincidência entre o maior incremento na população de adultos de $R$. palmarum e a época chuvosa pode ser atribuído ao fato de que nesta época as fibras que compõem o casulo da pupa tornam-se mais macios, pelo efeito da água, o que facilita o adulto emergir. $\mathrm{Na}$ época seca, essas estruturas tornam-se rígidas, podendo aprisionar e levar o inseto à morte.

Figura 1 - Dados de precipitação mensais de 2009 e 2010 do município de Sinop-MT, fornecidos pela EMPAER Sinop - INMET.

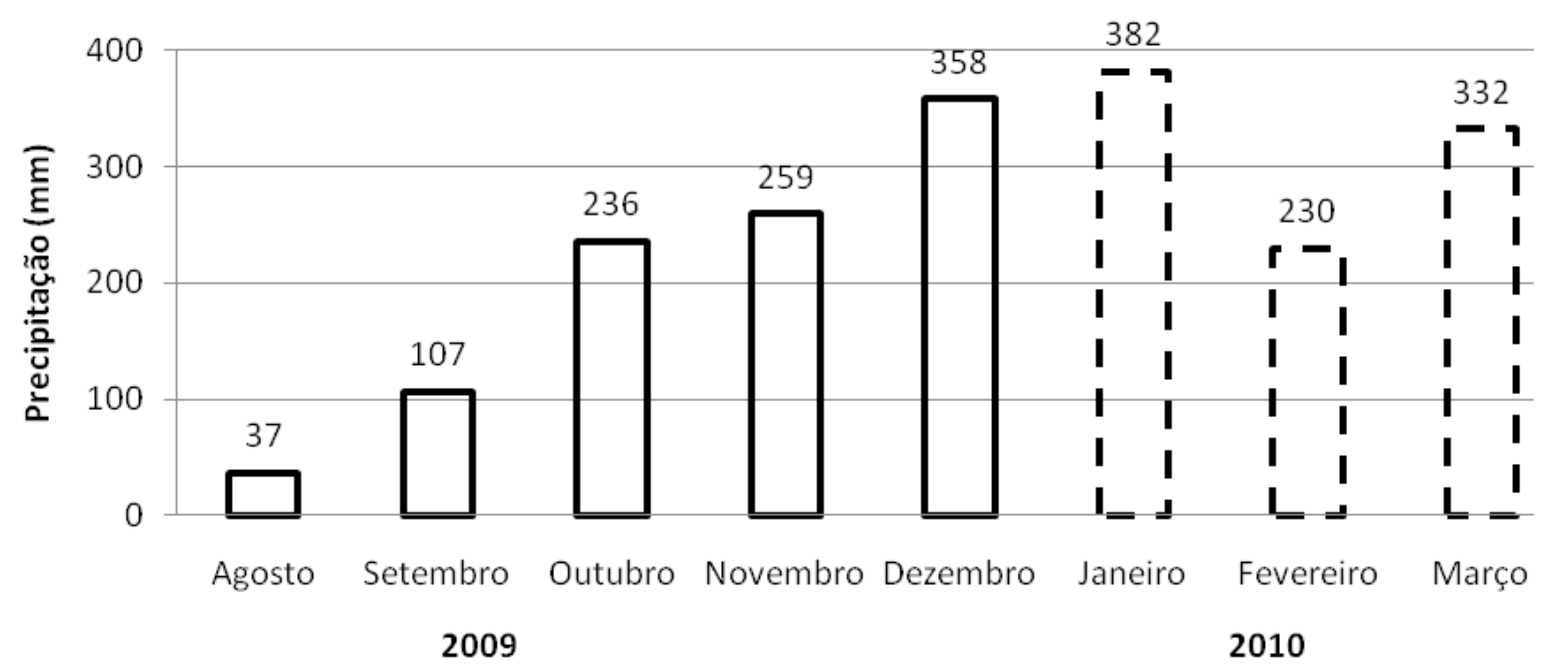

Fonte: Autores. 


\section{Distribuição e Controle}

\section{Broca-do-olho-do-coqueiro - Rhynchophorus palmarum}

Rhynchophorus palmarum tem origem no continente americano, ocorrendo desde a Argentina até a Califórnia, incluindo as Antilhas, e já no século XVI era conhecida no Brasil como praga do coqueiro (BONDAR, 1940). Sua presença tem sido constatada nos estados do Amazonas, Acre, Ceará, Pará, Maranhão, Paraíba, Pernambuco, Bahia, Minas Gerais, Rio de Janeiro, São Paulo, Paraná, Rio Grande do Sul (SILVA et al., 1968), Rio Grande do Norte, Alagoas e Sergipe (FERREIRA; WARWICK; SIQUEIRA, 1998). Foi registrado pela primeira vez na região centro-oeste, no estado do Mato Grosso do Sul, em agosto de 2001, no município de Três Lagoas por Soto e Nakano (2002). No Mato Grosso ainda não tinha ocorrido registro desta espécie.

Visando o seu controle, caso a planta morra pela ação de $R$. palmarum ou pela doença anelvermelho, ela deve ser imediatamente cortada e queimada, principalmente a parte apical, para prevenir a multiplicação e disseminação da praga (FERREIRA; WARWICK; SIQUEIRA, 1998). Deve-se evitar ferimentos nas plantas sadias durante os tratos culturais e na colheita, caso isso ocorra deve-se pincelar os ferimentos com piche, inseticida ou óleo queimado (FERREIRA, 2006b).

Recomenda-se a utilização de armadilhas Tipo Balde para capturar a praga, usando como atrativos o abacaxi (DUARTE et al., 2003) ou a cana-deaçúcar (TIGLIA et al., 1998). Esses mesmos autores relataram que uma forma de melhorar o atrativo seria utilizar junto com a armadilha o feromônio Rhynchophorol (2(E)-6metil-2-hepta-4-ol) potencializando e melhorando a coleta.

O fungo Beauveria bassiana é um agente natural com grande potencialidade de reduzir a população da broca em campo (FERREIRA, 2002). Sua liberação em programas de controle de praga pode ser feita tanto via machos infectados como através de iscas atrativas inoculadas. Nessa última técnica, os adultos são atraídos para as armadilhas de autocontaminação, e, uma vez contaminados nas iscas, passam a atuar como vetor do patógeno (FERREIRA; ARAÚJO; SARRO, 2001). Moura e Busoli (2006) citaram que a espécie Billea rhynchophorae é um tachinídeo que esteve presente em levantamentos de campo em áreas de dendê na Bahia, apresentando taxas de parasitismo de até $57 \%$ sobre R. palmarum.

\section{Broca-do-estipe-do-coqueiro - Rhinostomus barbirostris}

A Broca-do-estipe-do-coqueiro está localizada na região litoral sul do estado do Alagoas (VIVEIROS et al., 2002), pode ser encontrada comumente nos estados do Maranhão, Minas Gerais, Pará, Paraíba, Pernambuco, Piauí, Rio Grande do Sul, Sergipe, São Paulo e em alguns países como Argentina, Uruguai, México, Trinidad e Tobago, Honduras (FERREIRA, 2006b). No Mato Grosso, Silva (2009) relatou sua presença em Cotriguaçu e, agora, tem seu primeiro registro na região de Sinop.

Inspeções devem ser constantes no coqueiral para detectar os locais de postura e destruí-los mediante raspagem com o facão. Podem ser feitas também a derrubada e a queima das plantas fortemente infestadas e sem condições de recuperação, a fim de reduzir a propagação da praga (MIRISOLA FILHO, 2002).

A utilização de produtos sistêmicos para o controle de larva no interior do estipe não é eficiente, tornando-se eficaz se a ação do inseticida for de contato, por meio de injeção concentrada nos orifícios de entrada das larvas, nos de saída dos adultos ou na copa do coqueiro infestado. A pulverização deve ser feita nas horas mais amenas do dia e com ausência de ventos fortes direcionada para os cachos e para as axilas foliares, ou seja, pulverização localizada (FERREIRA; WARWICK; SIQUEIRA, 1998). 


\section{Broca-do-pedúnculo-floral-do-coqueiro}

\section{Homalinotus coriaceus}

A praga é comumente encontrada na Argentina e alguns estados brasileiros, dentre eles: Amazonas, Bahia, Espírito Santo, Minas Gerais, Pará, Paraíba, Pernambuco, Paraná, Rio de Janeiro, Santa Catarina, Sergipe e São Paulo (FERREIRA; WARWICK; SIQUEIRA, 1998).

Visitas regulares devem ser realizadas na plantação prestes a entrar em produção, para que medidas de controle sejam planejadas e adotadas, tão logo sejam notados, no estipe os sulcos superficiais que indicam a presença da praga. É preciso realizar a limpeza da copa do coqueiro por ocasião da colheita, procedendo à remoção e queima das folhas e dos cachos secos, dos pedúnculos dos cachos colhidos, das espatas florais velhas e do ingaço que sustenta as folhas para eliminar larvas e/ou pupas presentes nesses resíduos orgânicos (MIRISOLA FILHO, 2002).

O controle pode ser mecânico coletando e destruindo larvas, pupas e adultos da praga e biológico pelo uso do fungo Beauveria bassiana (cepa CPATC/057). A pupa dessa espécie é parasitada por um díptero da família Tachinidae (Paratheresia sp.). Os produtos químicos devem ser de contato e baixo poder residual, visto que a pulverização é direcionada para o fruto, em intervalos de aplicação: trimestral no primeiro ano de tratamento e semestral nos anos subseqüentes (FERREIRA, 2006a).

Broca-rajada - Metamasius cinnamominus (Perty, 1832) \& Metamasius hemipterus hemipterus (Linnaeus, 1758)

Segundo Zorzenon Bergmanm e Bicudo (2000), os insetos do gênero Metamasius estão amplamente distribuídos no continente americano desde os Estados Unidos até o Brasil.

Zorzenon Bergmanm e Bicudo (2000) relataram
- que Metamasius hemipterus hemipterus apresentase distribuídos pelos estados de Alagoas, Amapá, Bahia, Espírito Santo, Rio de Janeiro, Minas Gerais, Pará, Paraná, Santa Catarina e São Paulo e Couturier, Oliveira e Beserra (1999) relatatram que Metamasius cinnamominus foi encontrando em Belém - PA, em inflorescências de bacabi e bacabade-azeite.

Soliman et al. (2009) obtiveram resultados significativos na eficiência da utilização de toletes de cana como atrativo para coleta de Metamasius spp. em armadilhas do tipo Balde. Zorzenon Bergmanm e Bicudo (2000) afirmaram que a limpeza da copa, o coroamento do solo e a destruição (queima e enterro) dos frutos imaturos caídos no solo e nas bainhas foliares são medidas adotas para reduzir a multiplicação desta praga.

Os resultados obtidos por Oliveira et al. (2010) evidenciam que o atrativo alimentar melaço, juntamente com o fungo Beauveria bassiana, podem ser utilizados de forma integrada no controle de M. hemipterus hemipterus na bananicultura, visto que a combinação dos mesmo contribui em $54,23 \%$ na atratividade do inseto. A mobilidade deste inseto associado à suscetibilidade ao fungo B. bassiana fazem do gênero Metamasius spp. um importante agente disseminador do fungo em bananeiras (PRESTES, 2005). Em condições de laboratório, verificou-se alta mortalidade provocada por Beauveria bassiana em adultos de Metamasius sp. indicando patogenicidade. Observou-se 95,8\% de mortalidade quando os adultos da broca-rajada foram mergulhados na suspensão fúngica, sendo que $87,5 \%$ destes apresentaram esporulação do fungo (SOLIMAN et al., 2007).

Na região do Vale do Ribeira/SP, foi detectada Diaughia angusta (Diptera: Tachinidade) como espécie de parasitóide obtida de pupas de Metamasius, atingindo taxas de parasitismo de até $30 \%$ (NIHEI; PAVARINI, 2011). 
Broca-do-peciolo ou Broca-da-ráquis-foliar Amerrhinus ynca

O Amerrhinus ynca, conforme Bondar (1940) é particularmente daninho na Bahia, onde ocorre em quase todos os coqueirais. A broca-do-pecíolo é comumente encontrada nos estados Alagoas, Amazonas, Bahia, Espírito Santo, Pará, Paraná, Rio de Janeiro, São Paulo e Sergipe (FERREIRA, 2006a).

Uma alternativa de controle é realizar podas cortando e queimando as folhas danificadas. Segundo Ferreira, Warwick e Siqueira (1998), a realização de podas durante um período de um ano, pode diminuir a população de Amerrhinus ynca em até 65\%. A partir do momento em que sinais da praga forem encontrados em uma plantação, é fundamental que seja feita, também, uma fiscalização permanente das plantas para evitar a disseminação da praga.

O controle químico pode ser feito com uma aplicação direcionada aos orifícios das larvas, adotando-se os seguintes procedimentos: a) com o auxilio de um ferro de ponta fina fazer um furo na ráquis da folha, acima do local da oviposição até encontrar o canal da larva; b) encontrado o canal, injetar a calda inseticida; c) em seguida fechar o orifício com sabão. Trata-se de uma prática trabalhosa que ameniza o problema se for efetuada corretamente, para isso requer pessoas treinadas (FERREIRA, 2006a).

\section{Agradecimento}

Nosso especial agradecimento ao Prof. Dr. Germano Henrique Rosado Neto (UFPR) pela identificação dos insetos. Esta é a publicação número 21 da série técnica do Núcleo de Estudos Biológicos da Amazônia Meridional - NEBAM/UFMT.

\section{Referências}

AMBROGI, B. G.; VIDAL, D. M.; ZARBIN, P. H. G.; ROSADO-NETO, G. H. Feromônios de agregação em curculionidae (Insecta: Coleoptera) e sua implicação taxonômica. Química Nova, São Paulo, v. 32, n. 8, p. 2151-2158, 2009.

ARAUJO, R. P. C.; PEREIRA, J. B. A. Avaliação da oscilação populacional do Rhynchophorus palmarum (Coleoptera: Curculionidae) em função dos fatores climáticos e determinação das áreas focos em um coqueiral. In: CONGRESSO BRASILEIRO DE ENTOMOLOGIA, 17., 1998. Anais... Rio de Janeiro: SEB, 1998.

ARLEU, R.J. Dinâmica populacional e controle do Cosmopolites sordidus (Germ., 1824) e Metamasius hemipterus L., 1764 (Col: Curculionidae), em bananais da cv. Prata, no Espírito Santo. 1982. 55p. Dissertação (Mestrado) - Escola Superior de Agricultura "Luiz de Queiroz", Universidade de São Paulo, Piracicaba.

AZERÊDO, G. A.; COSTA, R. G.; MEDEIROS, M. B. Flutuação populacional da broca-da-bananeira (Cosmopolites sordidus germar, 1824) (Col.: Curculionidae) no brejo paraibano. Agropecuária Técnica, v. 19, n. 1/2, p. 84-88, 1998.

BONDAR, G. Insetos nocivos e moléstias do coqueiro (Cocos nucifera) no Brasil. Bahia: Tipografia Naval, 1940.

COUTURIER, G.; OLIVEIRA, M. S. P.; BESERRA, P. Entomofauna fitófaga em palmeiras nativas da Amazônia. Belém, PA: Embrapa Amazônia Oriental, 1999. (Centro de Pesquisas Agroflorestal, n. 2).

DUARTE, A. G.; LIMA, I. S.; NAVARRO, D. M. A.F.; SANT'ANA, A. E. G. Captura de Rhynchophorus palmarum L. (Coleoptera: Curculionidae) em armadilhas iscadas com o feromônio de agregação e compostos voláteis de frutos do abacaxi. Revista Brasileira de Fruticultura, Jaboticabal, v. 25, n. 1, p. 81-84, abr. 2003.

FARIA, W. S.; GAÍVA, H. N.; PEREIRA, W. Comportamento de cinco genótipos de coqueiro (Cocos nucifera 1.) na fase de germinação e de crescimento de mudas, sob diferentes sistemas de produção. Revista Brasileira de Fruticultura, Jaboticabal, v. 24, 2002.

FERREIRA, J. M. S. Controle biológico do agente transmissor do nematóide causador do anel vermelho do coqueiro. Aracaju: Embrapa Tabuleiros Costeiros, 2002. (Circular Técnica). 
Cultivo e controle de pragas e doenças do coqueiro. In: SEMANA DO FAZENDEIRO, 28., 2006, Uruçuca. Anais... Uruçuca: CEPLAC/CENEX/EMARC, 2006b. p. 15-23.

Produção integrada de coco: pragas do coqueiro no Brasil de A a Z. Aracaju: Embrapa, 2006a. CD-ROM.

FERREIRA, J. M. S.; WARWICK. D. R. N.; SIQUEIRA, L. A. A cultura do coqueiro no Brasil. 2. ed. Aracaju: Empresa Brasileira de Pesquisa Agropecuária, 1998.

FERREIRA, J. M. S.; ARAÚJO, R. P. C.; SARRO, F. B. Armadilha pet para captura de insetos adultos da broca-do-olho-do coqueiro, Rhynchophorus palmarum. Aracaju: Embrapa Tabuleiros Costeiros, 2001. 15p. (Embrapa Tabuleiros Costeiros. Circular técnica, 22).

FERREIRA, J. M. S.; LEAL, M. L. S.; SARRO, F. B.; ARAÚJO, R. P. C.; MOURA, J. I. L. Avaliação de diferentes fontes atrativas e suas prováveis interações na captura de Rhynchophorus palmarum. Manejo Integrado de Plagas y Agroecología, Costa Rica, n. 67, p. 23-29, 2003.

FONTES, H. R.; FERREIRA, J. M. S.; SIQUEIRA, L. A. Sistema de produção para a cultura do coqueiro. Aracaju: Embrapa Tabuleiros Costeiros, 2002. (Embrapa Tabuleiros Costeiros. Sistemas de Produção, 1).

IBGE. Seção cidades. Disponível em: <http://www.ibge. gov.br/cidadesat/topwindow.htm?1>. Acesso em: 5 jun. 2009.

JAFFÉ, K.; SÁNCHEZ, P.; CERDA, H.; HERNÁNDEZ, J. V.; JAFFÉ, R.; URDANETA, N.; GUERRA, G.; MARTÍNEZ, R.; MIRAS, B. Chemical ecology of the palm weevil Rhynchophorus palmarum (L.) (Coleoptera: Curculionidae): attraction to host plants and to a maleproduced aggregation pheromone. Journal of Chemical Ecology, New York, v. 19, p. 1703-1720, 1993.

LACERDA, J. I. Coqueiro sob ataque. Revista Cultivar Hortaliças e Frutas, out./nov. 2001. Disponível em: $<\mathrm{http}$ ://www.grupocultivar.com.br/site/content/artigos/ artigos.php?id=323>. Acesso em: 7 nov. 2010.

LEPESME, P. Les insectes des palmiers. Paris: Paul Lechevalier, 1947.

MIRISOLA FILHO. L. Â. Cultivo de Coco Anão. Viçosa: Aprenda Fácil, 2002.

MOURA, J. I. L.; RESENDE, M. L. V.; SGRILLO, R.; NASCIMENTO, L. A. R.. Diferentes tipos de armadilhas e iscas no controle de Rhynchophorus palmarum L. (Coleoptera: Curculionidae). Agrotrópica, Itabuna, p. 165-169, 1990.

MOURA, J. I. L.; VILELA, E. F. Pragas do coqueiro e dendezeiro. 2. ed. Viçosa: Aprenda Fácil, 1998.

MOURA, J. I.L.; BUSOLI, A. C. Manejo integrado de Rhybchophorus palmarum L. no agroecossistema do dendezeiro no Estado da Bahia. Jaboticabal: Funep, 2006. 60p.

NIHEI, S. S.; PAVARINI, R. Taxonomic redescription and biological notes on Diaugia angusta (Diptera, Tachinidae): parasitoid of the palm boring weevils Metamasius ensirostris and M. hemipterus (Coleoptera, Dryophthoridae). Zookeys, Bulgaria, n. 84, p. 23-38, 2011.

OLIVEIRA, F. Q.; MALAQUIAS, J. B.; FERREIRA, L. L.; RIBEIRO, T. da S.; ANICETO, R. R. Avaliação em campo da compatibilidade entre melaço e Beauveria bassiana no controle de Metamasius hemipterus horn, 1873 (Coleoptera: Curculionidae). Revista Verde de Agroecologia e Desenvolvimento Sustentável, Mossoró, v. 5, n. 4, p. 185-189, out./dez. 2010.

PAVARINI, R.; PAVARINI, G. M. P.; GOMES, J. M.; PINOTTI, É. B.; MARZOLA, D; RESENDE, R. Influência das diferentes estações do ano na ocorrência de adultos de Cosmopolites sordidus. Revista Eletrônica de Agronomia, Garça, v. 16, n. 2, p. 7-11, dez. 2009.

PRESTES, T. M. V. Dinâmica Populacional de Cosmopolites sordidus (Coleoptera: Curculionidae) em bananal, C.V. Nanicão, em São Miguel do Iguaçu, PR, e a susceptibilidade a isolado de Beauveria bassiana. 2005. 86 f. Tese. (Mestrado em Agronomia). Universidade Estadual do Oeste do Paraná. Marechal Cândido RondonPR, 2005.

SALOMÃO, L. C. C.; SIQUEIRA, D. L. Coco-da-baía. In: PAULA JÚNIOR, T. J.; VENZON, M. (Coord.). 101 Culturas: manual de tecnologias agrícolas. Belo Horizonte: EPAMIG, 2007. p. 285-298.

SARRO, F. B.; CROCOMO, W. B.; FERREIRA, J. M. S. Aspectos da biologia e morfologia da broca do pedúnculo floral do coqueiro, Homalinotus coriaceus (Coleoptera: Curculionidae). Neotropical Entomology, Londrina, v.33, jan./fev. 2004.

SILVA, A. G. A.; GONÇALVES; C. R.; GALVÃO, D. M.; GONÇALVES, A. J. L.; GOMES, J.; SILVA, M. N.; SIMONI, L. Quarto catálogo dos insetos que vivem nas plantas do Brasil, seus parasitos e predadores, parte 2, tomo 1o, insetos, hospedeiros e inimigos naturais. Rio de Janeiro: Ministério da Agricultura, 1968.

SILVA, C. G. Estudo do Comportamento da Broca da Bananeira Cosmopolites sordidus (GERMAR, 1824) (Col. Curculionidae), Visando ao Seu Controle. Piracicaba-SP, 1985. 82p. Tese para Doutoramento em Ciências na Área de Entomologia. ESALQ. 
SILVA, M. M. Diversidade de insetos em diferentes ambientes florestais no município de Cotriguaçu, Estado de Mato Grosso. 2009. Dissertação (Mestrado em Ciências Florestais e Ambientais) - Universidade Federal de Mato Grosso. Faculdade de Engenharia Florestal. Cuiába, 2009.

SOLIMAN, E. P.; PAVARINI, R.; GARCIA, V. A.; LIMA, R. C.; NOMURA, E. S.; PAVARINI, G. M. P.; DAMATTO JUNIOR, E. R. Diferentes iscas atrativas para monitoramento populacional de Metamasius sp. (Coleoptera: Curculionidae) no cultivo da pupunheira. Revista Eletrônica de Agronomia, Garça, v. 16, n. 2, p. 1-6, dez. 2009.

SOLIMAN, E. P.; PAVARINI, R.; GARCIA, V. A.; LIMA, R. C. Estudo preliminar da patogenicidade de Beauveria bassiana para controle de Metamasius sp (Coleoptera: Curculionidade) praga da pupunheira. In: SIMPÓSIO DE CONTROLE BIOLÓGICO, 10., 2007, Brasília. Anais... Brasília: [s. n.], 2007.

SOTO, S. S.; NAKANO, O. Registro de Rhynchophorus palmarum L. (Coleoptera: Curculionidae) no Estado de Mato Grosso do Sul. Neotropical Entomology, Londrina, v. 31, n. 4, out./dez. 2002.

SOUZA, R. M. Sinais envolvidos na comunicação de Amerrhinus ynca Sahlberg, 1823 (Coleoptera: Curculionidae). 2006. Dissertação (Mestre em Produção Vegetal) - Centro de Ciências e Tecnologias Agropecuárias, Universidade Estadual do Norte Fluminense Darcy Ribeiro, 2006.

TIGLIA, E. A., VILELA, E.; MOURA, J. I. L.; ANJOS, N. Eficiência de armadilhas com feromônio de agregação e cana-de-açúcar na captura de Rhynchophorus palmarum (L.) Anais da Sociedade Entomológica do Brasil, Londrina, v. 27, n. 2, jun. 1998.

VIVEIROS, A. J. A.; SANTIAGO, A. D; VIEIRA, J. C.; PITTA, J. E. P.; BRICEÑO, S. R. Diagnóstico fitossanitário dos coqueirais do Estado de Alagoas. In: CONGRESSO BRASILEIRO DE FRUTICULTURA, 2002. Anais... Belém, 2002. CD-Rom.

VERA, D; ORELLANA F. Control of Rhynchophorus palmarum in plantations of coconut and oil palm by trapping of adults. Boletín Técnico del Instituto Nacional de Investigaciones Agropecuarias Ecuador no. 198. 1988.

ZORZENON, F. J.; BERGMANM, E. C.; BICUDO, J. E. A. Primeira ocorrência de Metamasius hemipterus (LINNAEUS, 1758) e Metamasius ensirotris (GERMAN, 1824) (Coleoptera: Curculionidae) em palmiteiros dos gêneros Euterpe e Bactris (Arecaceae) no Brasil. Arquivos do Instituto Biológico, São Paulo, v. 67, n. 2, p. 265-268, 2000.
Recebido em 01 de junho de 2011 Aceito em 20 de abril de 2012 